\title{
Key Technologies for Ultra Large-scale Integration
}

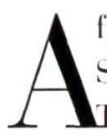
fter over 30 years of efforts, scientists at the CAS Shanghai Institute of Microsystem and Information Jechnology (SIMITT) made a technical breakthrough in producing the silicon-on-insulator (SOI) and 12-inch large silicon wafers, and realized its industrialization. In addition, they established China's first enterprise standard of SOI technology and enabled the products to enter the international high-end silicon-based materials market. This breakthrough earned the first prize of the National Science and Technology Progress Award in 2016 and the 2017 Outstanding Science and Technology Achievement Prize of the Chinese Academy of Sciences.

Through 7 years of study, scientists at the CAS Institute of Microelectronics (IME) made breakthroughs in multiple key technologies, including $22-\mathrm{nm} \mathrm{High}-\mathrm{k} /$ metal gate technologies, 1+-nm FinFETs, novel flash devices and manufacturability design. These breakthroughs, which have been awarded a total of 2,406 patents, including 483 international ones, have laid a systematic intellectual property foundation for a spectrum of key technology joints. In 2013, a license transfer was made between the research institute and large manufacturing companies in China, marking the beginning of the industrialization stage of the R\&D results. This achievement, winning the 201t Outstanding Science and Technology Achievement Prize of the Chinese Academy of Sciences, has provided key supports for the technical upgrade of China's nano-scale Ultra Large-scale Integration (ULSI) industry.

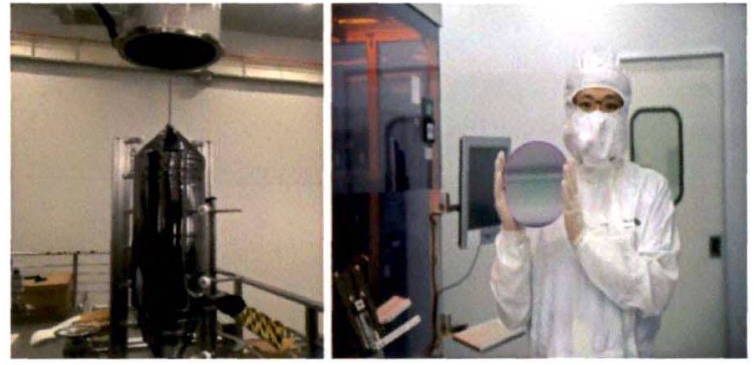

The production of 12-inch large silicon wafers. (Credit: SIMIT)

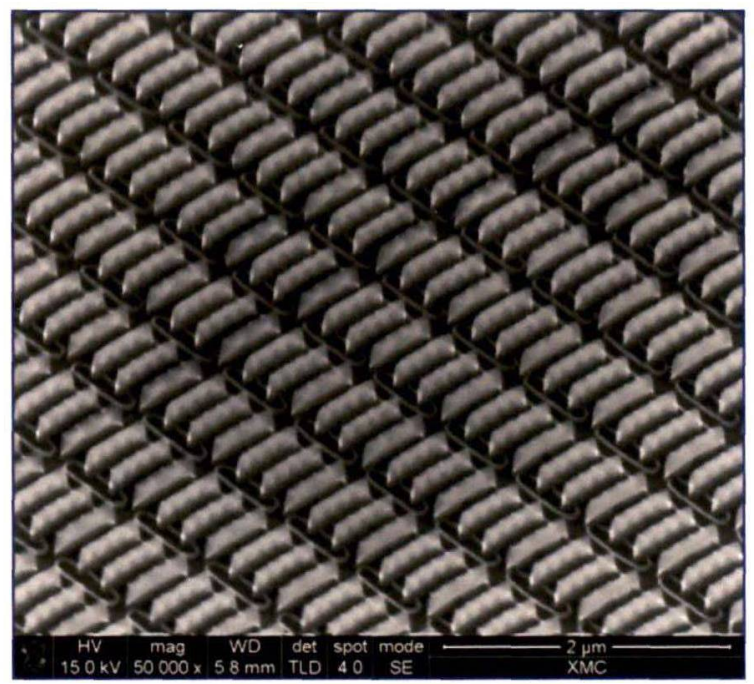

Large-scale bulk silicon FinFET device array. (Credit: IME) 